\title{
LEY DE SIMPLIFICACIÓN Y PROGRESIVIDAD TRIBUTARIA: ANÁLISIS DE SU INCIDENCIA EN LA TRIBUTACIÓN DE LAS MICROEMPRESAS ECUATORIANAS
}

\section{Law of Simplification and Tax Progressivity: Analysis of its impact on the taxation of Ecuadorian micro-enterprises}

\author{
Nallely Anahi Carrillo Quinto, Est. \\ Universidad Estatal de Milagro, Ecuador \\ https://orcid.org/0000-0001-8087-6851 \\ ncarrilloq@unemi.edu.ec
}

\author{
Gloria Angelica Valderrama Barragán, MsC. \\ Universidad Estatal de Milagro, Ecuador \\ https://orcid.org/0000-0002-1491-1548 \\ gvalderramab@unemi.edu.ec
}

Palabras claves: Microempresarios, Simplicidad, Progresividad.

Keywords: Micro Entrepreneurs, Simplicity, Progressivity.
Recibido: 30 de diciembre de 2020

Aceptado: 18 de marzo de 2021

\section{RESUMEN}

El presente artículo se realiza para dar a conocer como regirá la nueva Ley llamada "Ley Orgánica de Simplificación y Progresividad Tributaria", que, según el Ejecutivo, con ella se recaudará más dinero que se utilizará para cubrir el endeudamiento público, de la misma manera utilizará para simplificar trámites para que las empresas se incentiven a cumplir con los pagos establecidos y deberá cumplir con el principio de progresividad. De forma que, esta investigación se enfoca exclusivamente en los microempresarios, puesto que, con el nuevo reglamento, la tributación en el país dará un giro de $180^{\circ}$, de manera que puede afectar o beneficiar a este tipo de empresas, las mismas que habitualmente pueden contar con diferentes errores comunes, así como, el no llevar un correcto control financiero. Esta investigación se desarrolló con un enfoque cualitativo, de tipo descriptivo y exploratorio, puesto que la metodología consiste en leer esta nueva ley, para analizarla y describir los rasgos relacionados a la temática.

\begin{abstract}
This article is done to publicize how the new "Tax Progressivity and Simplification Act" will govern the new Act, which, according to the Executive, will raise more money to be used to cover public debt, in the same way it will use to simplify procedures for companies to incentivize themselves to comply with the established payments and must comply with the principle of progressivity. So this research focuses exclusively on micro entrepreneurs, since, with the new regulation, taxation in the country will take a turn of $180^{\circ}$, so that it can affect or benefit this type of company, the same ones that can usually count on different common mistakes, as well as, the failure to carry out a proper financial control. This research was developed with a qualitative approach, descriptive and exploratory, because the methodology consists of reading this new law, to analyze it and describe the features related to the topic.
\end{abstract}




\section{INTRODUCCIÓN}

El endeudamiento del país, más el bajo precio del principal producto de exportación ha llevado al Presidente de la República del Ecuador a tomar decisiones que colaboren a cubrir ese déficit, motivo por el cual realizó varios intentos de reformas, como eliminar el subsidio de la gasolina, que no se publicó en el Registro oficial; después creó la Ley Orgánica de Simplificación y Progresividad Tributaria, que aumentarán los impuestos a pagar, así mismo ayudará a la producción local, y como su nombre lo indica a simplificar trámites.

De manera que, en el presente artículo se analizará la nueva Ley Orgánica de Simplificación y Progresividad Tributaria y su incidencia en la tributación, con un enfoque en las microempresas donde se observará cómo se verán afectadas al momento de tributar, cuáles serán los nuevos plazos establecidos, sus nuevas obligaciones o beneficios.

Es por ello, que, en resumen, el objetivo general de este artículo es analizar la afectación del nuevo reglamento tributario en las microempresas; su cumplimiento se hará efectivo mediante pasos como: conocer las disposiciones del reglamento; especificar de manera resumida el reglamento enfocado en las microempresas; $y$, detallar las conclusiones de las disposiciones establecidas en la Ley.

\section{DESARROLLO}

El presente artículo se diseña bajo un enfoque cualitativo, según (Quecedo \& Castaño, 2002, pág. 12) realizar "estudios cualitativos es describir sistemáticamente las características de los fenómenos, relaciones causales, y explicar hipótesis creadas por datos canalizados, que pueden obtenerse para fines descriptivos o de análisis de estudios de tipo exploratorio".

Además de presentarse con una orientación de tipo exploratorio, de acuerdo a (Cabezas Mejía, Andrade Naranjo, \& Torres Santamaría, 2018, pág. 68) "el estudio exploratorio permite avanzar la investigación a través de la caracterización o descripción del fenómeno, se convierten en el insumo para investigaciones correlacionales" y es descriptivo porque "explica minuciosamente lo que sucede con el fenómeno e interpreta la situación" (Cabezas Mejía, Andrade Naranjo, \& Torres Santamaría, 2018)

\section{Resultados}

La economía en Ecuador se ha deteriorado en los últimos años, debido al alto nivel de endeudamiento que existe y continúa en aumento, además de influir otros factores como el bajo precio de uno de los principales productos de exportación del país, el petróleo. El crecimiento de la deuda pública se puede constatar en los datos, expresados en millones de dólares americanos, que reposan en él (Instituto Nacional de Estadística y Censos, 2019), donde se puede observar que la deuda pública del Ecuador en el año 2009 era de $\$ 10234.70$, la cual aumentó y siguió en crecimiento hasta marzo del 2019 que es de $\$ 51214.80$, observando un aumento de $\$ 40980.10$.

Es por ello, que el Presidente de la República por medio de su potestad de crear proyectos de reformas económicas urgentes, en octubre de 2019, optó por implementar un paquete de medidas económicas a través del Decreto 883, en donde incluía la eliminación del subsidio de la gasolina, un tema que fue controversial y motivo por el cual se realizaron varias protestas en contra de ello; $y$, que después de un diálogo en aras de la paz, este decreto quedó derogado por el Ejecutivo. Debido a esto, se creó la Ley de Crecimiento Económico, sin embargo, la Asamblea Nacional del Ecuador no la aprobó, a lo que el Presidente remitió un nuevo proyecto llamado Ley Orgánica de Simplificación y Progresividad Tributaria.

Esta nueva ley hace referencia a la simplicidad, que es la forma de facilitar o ser más flexibles, y en la progresividad, que según (Mancilla Castro, 2015, pág. 83) es el "principio interpretativo que establece que los derechos no pueden disminuir, por lo cual, al solo poder aumen-tar, progresan gradualmente".

Además, según (El Universo, 2019), la nueva ley ayudará a recaudar 620 millones de dólares americanos, que se emplearán para cubrir el déficit fiscal. La aplicación de esta serie de reformas económicas será obligatoria a partir de su reconocimiento en el Registro Oficial, el mismo que se llevó a cabo el 31 de diciembre del 2019, y se comenzó a implementar desde el 1 de enero del 2020.

Estas medidas económicas, en relación a la parte tributaria, conlleva implícito el gran impacto que tendrá en los diferentes tipos de empresas que existen en el Ecuador, así mismo en los consumidores, que son los demandantes del servicio o bien. 
Una empresa según (Pereda Marín \& Berrocal Berrocal, 1999, pág. 16) la define como "organizaciones, con características comunes y diferentes; como tamaño, estructura, actividad; que tienen por objetivo primario obtener beneficios económicos a través de los productos o servicios que produce, vende o distribuye". Una empresa, es una unidad instituida, que nace con el objetivo de conquistar beneficios lucrativos.

Las empresas como lo indican Pereda y Berrocal, son diferente o comunes, de acuerdo al cumplimiento de ciertas características, es así que, en efecto, existen diferentes tipos o clasificaciones de la empresa, que se pueden categorizar por su actividad económica, su constitución, y por su tamaño.

Las empresas, que se integran según su tamaño son: microempresas, pequeñas, medianas y grandes; estas empresas se constituyen así por factores como ingresos y el número de empleados, según se presenta la siguiente tabla:

\section{Tabla 1}

Compañías según su tamaño

\begin{tabular}{|c|c|c|}
\hline Tipo & $\begin{array}{l}\text { Número de } \\
\text { trabajadores }\end{array}$ & Ingresos \\
\hline Microempresas & $1 \leq x \leq 9$ & $\leq \$ 100.000,00$ \\
\hline Pequeña & $10 \leq x \leq 49$ & $\$ 100.001,00 \leq x \leq \$ 1000000,00$ \\
\hline Mediana & $50 \leq x \leq 199$ & $\begin{array}{l}\$ 1000001,00 \leq x \leq \$ 5000 \\
000,00\end{array}$ \\
\hline Grande & $\geq 200$ & $\geq \$ 5000001,00$ \\
\hline
\end{tabular}

Elaboración propia, 2020.

Fuente: (Superintendencia de Compañías, Valores y Seguros, 2019)

Así también, según datos de la (Superintendencia de Compañías, Valores y Seguros, 2019) las microempresas son las que reinan en Ecuador con un $56,76 \%$, siguiendo las pequeñas con un $28,77 \%$, medianas con $10,17 \%$ y las grandes con $4,30 \%$.

Esta institución pública, arroja estadísticas y permite observar que las microempresas son las que predominan dentro del territorio nacional. "Una microempresa, por lo general, realizan actividades comerciales informales, las cuales se rigen por parámetros de negocio, en los que se utiliza más la experiencia empírica, la capacidad y el gusto de trabajar conjuntamente con la necesidad de lograr un sustento familiar apropiado" (Benítez Gándara \& Morán Zurita, 2013, pág. $6)$.

Analizando el número de microempresas existentes, se logra concluir que son ellas, las más influyentes y las que componen el fragmento de la población emprendedora, a la que se necesita dar más atención, porque con su pequeño negocio permiten generar ingresos, empleos, poder adquisitivo y producción, los mismos que se constituyen como factores que mueven y benefician a la economía del país.

La presente Ley Orgánica de Simplificación y Progresividad Tributaria presenta varias reformas en medidas tributarias, en cuanto a las microempresas se estableció un régimen impositivo exclusivo para ellas. Este se presenta con el Título Cuarto-A que contienen únicamente 3 capitulados.

En el capítulo I de la (Ley Orgánica de Simplificación y Progresividad Tributaria, 2019, pág. 19) se detallan las normas generales expresando que: 
1. Se sujetarán a este régimen todos los contribuyentes que cumplan la categoría de microempresas, excepto los que estén inscritos al régimen impositivo simplificado;

2. Las microempresas que presten servicios profesionales, ocupación liberal, relación de dependencia, que perciban rentas de capital o los que suministren servicios digitales no podrán sujetarse a este régimen;

3. El Servicio de Rentas Internas fijará y categorizará a las microempresas por medio de un análisis de su base de datos;

4. EI SRI puede declarar de oficio la exclusión de empresas que no se categoricen dentro del concepto de microempresas, los cambios se reflejarán desde el siguiente ejercicio fiscal, a excepción de haber cumplido con el tiempo máximo de permanencia; $y$,

5. Los contribuyentes que estén acogidos a este régimen deberán emitir comprobantes de ventas, llevar contabilidad de acuerdo a la ley, presentar las declaraciones de impuestos y lo restante que implante el reglamento.

En el Capítulo II, titulado "Del impuesto a la renta" trata con relación a lo indicado en su título, específicamente, lo concerniente a las tarifas y pagos. En resumen, a estos artículos desde el 97.22 al 97.24 expresan que:

"Se aplicará, obligatoriamente a todas las microempresas, una tarifa del $2 \%$ sobre los ingresos brutos provenientes de actividades empresariales; si, las actividades fueran provenientes de otras fuentes se realizará el cálculo de acuerdo al régimen general del impuesto a la renta; además las microempresas pagarán el impuesto en forma de declaración anual en los plazos establecidos y no serán agentes de retención" (Ley Orgánica de Simplificación y Progresividad Tributaria, 2019, pág. 19)

En este capitulado se cumple el principio de simplicidad, debido a que sencillamente se va a realizar el cálculo directo del $2 \%$ sobre los ingresos brutos e inmediatamente pagar. No obstante, se puede perjudicar a este tipo de empresas puesto que no se tomará en cuenta si esta empresa tiene pérdida o utilidad en el ejercicio fiscal, pese a ello, se realizará de cualquier manera la ejecución del impuesto, trayendo consecuencias negativas para las microempresas en caso de haber pérdida, así, por ejemplo: alto riesgo de mortalidad como empresa dentro del mercado, en casos extremos.

En el Capítulo III "De los impuestos al valor agregado (IVA) y a los consumos especiales (ICE)", se enuncian las siguientes medidas de acuerdo a (Ley Orgánica de Simplificación y Progresividad Tributaria, 2019, pág. 19) que "los contribuyentes considerados como microempresarios, deberán presentar las declaraciones y realizarán el pago de los impuestos IVA e ICE de forma semestral; además no serán agentes de retención del IVA".

"Los impuestos tienen una participación muy importante dentro del Presupuesto General del Estado, son los que más contribuciones aportan, los que son destinados a financiar servicios y obras estatales, como, por ejemplo, servicios de educación, salud, infraestructura y entre otros" (Valderrama-Barragán, Valderrama-Barragán, \& Palacios-Anzules, 2017, pág. 609). Los impuestos son una parte esencial en cualquier país, de manera que su declaración es de vital importancia para la ciudadanía, en general.

En el presente capítulo se reforman dos de ellos, el IVA e ICE. El IVA es el impuesto al valor agregado que se le añade el $12 \%$ a productos o servicios que no son de primera necesidad. El ICE, es el impuesto a los consumos especiales, que al igual que, el impuesto anterior se aplica a consumos que nos relevantes para que un ser humano viva, se grava con un porcentaje a productos o servicios según el tarifario que imponga la ley, el mismo que se segmenta por grupos, así, por ejemplo: a los cigarrillos, gaseosas, productos alcohólicos y con la nueva reforma también a los planes pos pago de operadoras telefónicas.

Cumpliendo con el fragmento de simplicidad, la ley constituye la declaración del impuesto al valor agregado (IVA), así como el impuesto a los consumos especiales (ICE) afecta a las microempresas en la forma de presentarlos y pagarlos, que deberá ser de forma semestral, es decir, dos veces al año. Sin embargo, desde un punto de vista más profundo, al hablar de microempresas, queremos mencionar a los pequeños negocios que habitualmente son familiares, emprendimientos que, empíricamente se observa que necesitan conocer más sobre el control financiero, por ejemplo, llevar un control de ingresos y gastos; que, con el paso del tiempo, deberán ir progresando e ir implementando la contabilidad y desde luego los estados financieros.

Es así que se concluye, que la mayoría de las microempresas no llevan un correcto registro financiero que permita observar la liquidez de la empresa y su capacidad de endeudamiento, de manera que el pago de los impuestos semestralmente será más complicado al realizarlo porque no se conocerá con certeza el valor a pagar con respecto a los impuestos, debido a la falta de cultura tributaria y control financiero de la empresa.

Así como este apartado en la Ley, se observan otras como: 
Con respecto al ICE, existen varios grupos en los cuales se aplica el impuesto, este reglamento reformó las tarifas, sin embargo, nos centraremos específicamente en el grupo IV de tarifa mixta, que en una nota explica el beneficio que se le otorga a las microempresas. A continuación, se muestra la tabla:

Tabla 2

Tarifa mixta de bienes gravados con ICE

\section{GRUPO IV}

Tarifa mixta

\begin{tabular}{llc}
\hline \multicolumn{1}{c}{ Descripción } & Tarifa específica & $\begin{array}{c}\text { Tarifa ad valorem } \\
\text { (según el valor) }\end{array}$ \\
\hline Cigarrillos & USD 0,16 por unidad & No aplica \\
\hline Alcohol & $\begin{array}{l}\text { USD 7,22 por litro de } \\
\text { alcohol puro }\end{array}$ & $75 \%$ \\
& USD 7,25 por litro de & $75 \%$ \\
\hline Bebidas alcohólicas & alcohol puro \\
& USD 1,5 por litro de & $75 \%$ \\
\hline Cerveza artesanal & alcohol puro & \\
& & \\
\hline $\begin{array}{l}\text { Cerveza industrial de pequeña } \\
\text { escala (participación en el }\end{array}$ & alcohol puro por litro de \\
mercado ecuatoriano de hasta & \\
730.000 hectolitros) &
\end{tabular}

Cerveza industrial de mediana USD 10,58 por litro de $\quad 75 \%$ escala (participación en el alcohol puro mercado ecuatoriano de hasta 1.400 .000 hectolitros)

$\begin{aligned} & \text { Cerveza industrial de } \\ & \text { escala }\end{aligned}$
$\begin{gathered}\text { alcohol puro } \\ \text { aSD } 13,20 \text { por litro de }\end{gathered}$

(participación en el mercado ecuatoriano superior a 1.400 .000 hectolitros) 
En la tabla se establecen valores reformados para el pago del impuesto a los consumos especiales. De manera que se indica que para las empresas que produzcan el alcohol y las bebidas alcohólicas elaboradas con al menos un $70 \%$ con ingredientes nacionales que sean comercializadas por una microempresa o artesanos, por ejemplo: la producción de alcohol de caña de azúcar cultivada dentro del Ecuador, la tarifa específica tendrá un descuento de hasta un $50 \%$ según lo que conforme la Ley. Cabe recalcar que en caso de la cerveza se aplicará esta normativa a marcas que estén dando sus inicios en el mercado.

Este inciso, beneficia mucho a la empresa micro de agricultura, de forma que los comercializadores o productores de alcohol aspiran más descuentos, por ende, visitarán a una microempresa a consumir el bien, y se puede escuchar palpitar el aumento en los ingresos de la compañía. $\mathrm{O}$, de otra manera, se puede dar el caso de tener al contribuyente de una microempresa que se dedica a la elaboración de cervezas, podrá acogerse a este sistema para obtener una rebaja de los tributos.

Además, se establece en el artículo 5 de la (Ley Orgánica de Simplificación y Progresividad Tributaria, 2019) que los GADs (Gobiernos Autónomos Descentralizados) municipales de la provincia de Manabí y Esmeraldas instalarán a través de una ordenanza, la condonación del $100 \%$ de las deudas tributarias y no tributarias vencidas al 30 de septiembre de 2019, para las microempresas de acuerdo a la clasificación establecida en el Reglamento de Inversiones del Código Orgánico de la Producción, organizaciones inscritas en la Superintendencia de Economía Popular y Solidaria, que todavía mantienen afectación económica a consecuencia del terremoto ocurrido el pasado 16 de abril del 2016, para lo cual se describirá mediante un informe técnico de órgano competente en cada GAD, donde se evidenciará dicha afectación.

En resumen, las microempresas situadas en las provincias de Manabí y Esmeraldas que todavía posean afectación en relación monetaria, se les condonará las deudas tributarias mediante acción de los respectivos municipios a través de un informe que desagregue esa información

Existen también ciertas disposiciones generales, a las que deben suscribirse las microempresas y son: "las normas tributarias que se constituyen en esta ley, serán aplicadas a partir de su publicación en el debido Registro Oficial y el SRI como organismo regulador y recaudador del tributo, tiene un plazo de 20 días desde su publicación en el Registro Oficial para categorizar a las microempresas e incluirlas en el nuevo régimen" (Ley Orgánica de Simplificación y Progresividad Tributaria, 2019).

\section{CONCLUSIÓN}

El Servicio de Rentas Internas deberá categorizar a las microempresas, según como lo ordena la ley.

Las microempresas declararán el Impuesto a la Renta, mediante un cálculo simple, de manera que será el 2\% sobre los ingresos brutos obtenidos de la actividad comercial, no teniendo opción a deducir los gastos o costos incurridos. En caso, de que la microempresa realice otras actividades no relacionadas a su actividad comercial, el cálculo será el que se ejecuta por lo general.

Las microempresas tienen que declarar de forma semestral el Impuesto al Valor Agregado (IVA) y el Impuesto a los Consumos Especiales (ICE)

Según como lo establece la ley, las microempresas no serán agentes de retención.

Se espera que las microempresas dedicadas a la agricultura incrementen los ingresos percibidos la venta de sus productos, de manera que las empresas o productores buscan descuentos ofrecidos por el ente recaudador al comprar a este tipo de empresas.

Las microempresas ubicadas en la provincia de Manabí y Esmeraldas podrán gozar de la condonación del total de sus deudas o créditos tributarias a pagar, si realizan el trámite oportuno ante el debido Gobierno Autónomo Descentralizado del cantón al que pertenecen, siempre y cuando evidenciando el déficit económico que tuvieren a partir del desastre natural ocurrido el 16 de abril del 2016.

\section{BIBLIOGRAFÍA}

1. Benítez Gándara, F. J., \& Morán Zurita, A. P. (2013). Estudio de la contribución de las micro y pequeñas empresas en la distribución más equitativa del cantón Quito. Quito: Universidad Politécnica Salesiana. 
2. Cabezas Mejía, E. D., Andrade Naranjo, D., \& Torres Santamaría, J. (2018). Introducción a la metodología de la investigación científica. Sangolquí: Universidad de las Fuerzas Armadas ESPE.

3. El Universo. (9 de Diciembre de 2019). Qué dice la Ley de Simplicidad y Progresividad Tributaria que se debate en la Asamblea Nacional. Política.

4. Instituto Nacional de Estadística y Censos. (2019). Estadística de Deuda Pública del SPNF. Quito: Ministerio de Economía y Finanzas.

5. Ley Orgánica de Simplificación y Progresividad Tributaria. (31 de Diciembre de 2019). Registro Oficial. Quito, Ecuador. Obtenido de https://www.registroficial.gob.ec/media/k2/attachments/SRO111_20191231_LEY_.pdf

6. Mancilla Castro, R. G. (2015). El principio de progresividad en el ordenamiento constitucional Mexicano. Cuestiones constitucionales, 82-103.

7. Pereda Marín, S., \& Berrocal Berrocal, F. (1999). El entorno empresarial. La empresa, su organización y funcionamiento. Revista Complutense de Educación, 15-35.

8. Quecedo, R., \& Castaño, C. (2002). Introducción a la metodología de investigación cualitativa. Revista de Psicodidáctica, 5-39.

9. Sánchez Jiménez, V. (2015). La redefinición del papel de la empresa en la sociedad. Barataria, 129-145.

10. Superintendencia de Compañías, Valores y Seguros. (2019). Ranking Empresarial 2019. Obtenido de https://appscvs.supercias.gob.ec/rankingCias/\#rg

11. Valderrama-Barragán, G., Valderrama-Barragán, E., \& Palacios-Anzules, I. (2017). Impacto de la aplicación de instrumentos y controles de medida para la planificación tributaria. Dominio de las ciencias, 605-619. 